\title{
Study of correlation between age with incidence of endometrial cancer and histopathological type
}

\section{Ganesh Bharaswadkar*}

Department of Obstetrics and Gynaecology, BDF Hospital, Riffa, Kingdom of Bahrain

Received: 21 March 2021

Revised: 21 April 2021

Accepted: 26 April 2021

\author{
*Correspondence: \\ Dr. Ganesh Bharaswadkar, \\ E-mail: ganeshbbbb@gmail.com
}

Copyright: (C) the author(s), publisher and licensee Medip Academy. This is an open-access article distributed under the terms of the Creative Commons Attribution Non-Commercial License, which permits unrestricted non-commercial use, distribution, and reproduction in any medium, provided the original work is properly cited.

\begin{abstract}
Endometrial carcinoma is one of the commonest Gynecological malignancy. Endometrioid type is the most common type associated with hyper-estrogenic state and has better prognosis. While non endometrioid type is less common, associated with elderly age and has dismal prognosis. Uterine cancer is most often observed in higher age group with average age at diagnosis of 60 years. It most often occurs in women over 50.16 cases of endometrial carcinoma were collected from January 2018 until November 2020.The study evaluated the correlation of age with incidence and type of endometrial cancer by categorizing patients into different age groups and then analyzing them. The most affected age group was between 60-70 years and commonest type of endometrial cancer identified was Endometrioid type.
\end{abstract}

Keywords: Endometrial cancer, Endometrioid, Non-endometrioid

\section{INTRODUCTION}

Endometrial cancer is the one of the commonest Gynecologic malignancy. In Bahrain, the rates are 5.9 per 100,000 (IARC, WHO Globocan 2020 Bahrain) with mortality 1.2 per 100,000 and Incidence of $2.6 \%$ 5-year prevalence of 107 cases (IARC, WHO Globocan 2020 Bahrain) while in India, the rates are as low as 4.3 per $100,000 .{ }^{1}$ Ninety-seven percent of all cancers of the uterus arise from the endometrium. ${ }^{2}$ Grossly three quarters of cases are diagnosed at an early stage with a tumor confined to the uterine corpus. ${ }^{3}$ It comes fourth in line in aspect to prevalence after carcinomas of breast, colorectal, and lung in woman. ${ }^{4}$ In the United States, endometrial cancer has accounted for average 6000 deaths per year. ${ }^{5}$

Uterine cancer is most often observed in higher age group with average age at diagnosis of 60 years. It is less commonly seen in women younger than $45 .{ }^{14}$
Studies done so far have revealed that the most common type of endometrial carcinoma is endometrioid adenocarcinoma, which consisted of malignant glandular epithelial elements mixed with squamous metaplasia. ${ }^{6}$ It originates from endometrial hyperplasia in hyperestrogenic milieu. ${ }^{7}$ It is often preceded by endometrial intra-epithelial neoplasia, is associated with younger age of onset as compared to non-endometrioid type which includes serous or clear cell histology. Non-Endometrioid type is typically associated with older age, black race, absence of unopposed estrogen and presentation at advanced stages. ${ }^{8-12}$ It is characteristically more aggressive than endometrioid type and has a poorer prognosis. Clear cell and papillary serous carcinoma of the endometrium are histologically similar to those seen in the ovary and the fallopian tube, and the prognosis is worse for these tumors. ${ }^{13}$ Mucinous, squamous, and undifferentiated tumors are rarely observed. Endometrioid type accounts for $75 \%-80 \%$, while nonendometrioid type is seen in the rest. Serous carcinomas develop from "endometrial intraepithelial carcinoma," a 
lesion representing malignant transformation of the endometrial surface epithelium. ${ }^{7}$

Most endometrioid carcinomas develop in the setting of hyper-estrogenic milieu. These imbalances may result from absolute excesses of endogenous or exogenous estrogen or relative deficiencies of progesterone. Androgens and other growth factors may also have a role in this pathway, but this has not been evaluated.

Non endometrioid carcinoma typically develops in the background of atrophic endometrium in elderly woman. Risk factors for such tumors have not been identified, but available evidence suggests that excess estrogen exposure is not a risk factor for the development of such tumors and hence the only possible risk factor for this kind of tumour is age. Serous carcinomas are usually diagnosed in women over 60, and these neoplasms are exceedingly uncommon in younger women. Development of p53 mutation may represent the molecular identity of serous carcinoma and possibly define the entity in combination with morphology. ${ }^{7}$

This study attempts to find out correlation of age with incidence \& type of endometrial cancer.

\section{CASE SERIES}

A descriptive and retrospective study was performed using consecutive patients with the pathologic diagnosis of an endometrial cancer on endometrial sampling from January 1, 2018 to November 30, 2020, in Bahrain Defense Force Hospital, Kingdom of Bahrain. Cases diagnosed with endometrial carcinoma during study duration from January 2018 un till November 2020 were divided into 5 different age groups and also divided according to the type of endometrial cancer.

Table 1: Case statistics according to type of tumour.

\begin{tabular}{|ll|}
$\begin{array}{l}\text { Endometrioid } \\
\text { carcinoma }(\%)\end{array}$ & $\begin{array}{l}\text { Non-endometrioid } \\
\text { carcinoma }(\%)\end{array}$ \\
\hline $\mathbf{1 3}$ & 03 \\
\hline
\end{tabular}

Table 2: Age groups of patients with endometrial carcinomas.

\begin{tabular}{|c|c|c|}
\hline Age group (in years) & Cases & Percentage \\
\hline Below 40 & 1 & 6.2 \\
\hline 41-50 & 2 & 12.5 \\
\hline $51-60$ & 4 & 25 \\
\hline 61-70 & 6 & 37.5 \\
\hline Above 70 & 3 & 18.75 \\
\hline
\end{tabular}

Institutional Review Board approval was obtained before starting the study. In this study, 16 confirmed cases of Endometrial malignancies were examined to determine the most frequent type of cancer and its association with age. The age ranged from 35 to 75 years with the median age 60 . The age group most frequently affected with endometrial carcinoma is 60 and above representing $56 \%$ of all cases, 25\% cases in 51-60 years of age group followed by $12.5 \%$ cases in $41-50$ years' age group and least $6.25 \%$ in below 40 years of age. (Table 2). Out of 16 cases, $13 / 16(81.2 \%)$ had endometrioid carcinoma and $3 / 16(18.75 \%)$ had non-endometrioid type (Table 1).

Table 3: Frequency of different types of cancer with age range.

\begin{tabular}{|llll|}
\hline $\begin{array}{l}\text { Type of } \\
\text { cancer }\end{array}$ & Cases & $\%$ & Age range \\
\hline Endometrioid & 13 & 81.2 & $40-75$ years \\
\hline Papillary & 02 & 12.5 & $\begin{array}{l}\text { More than } 70 \\
\text { years }\end{array}$ \\
\hline Mucinous & 01 & 6.25 & 67 years \\
\hline
\end{tabular}

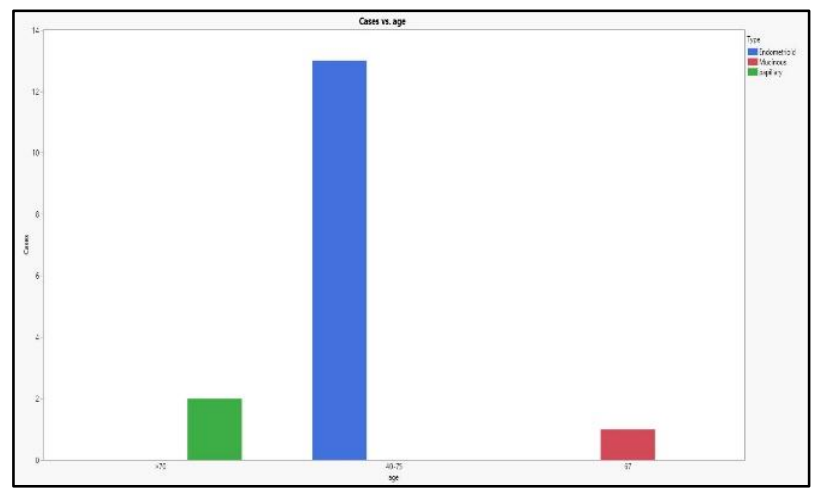

Figure 1: Correlation of age with histopathological type of endometrial carcinoma.

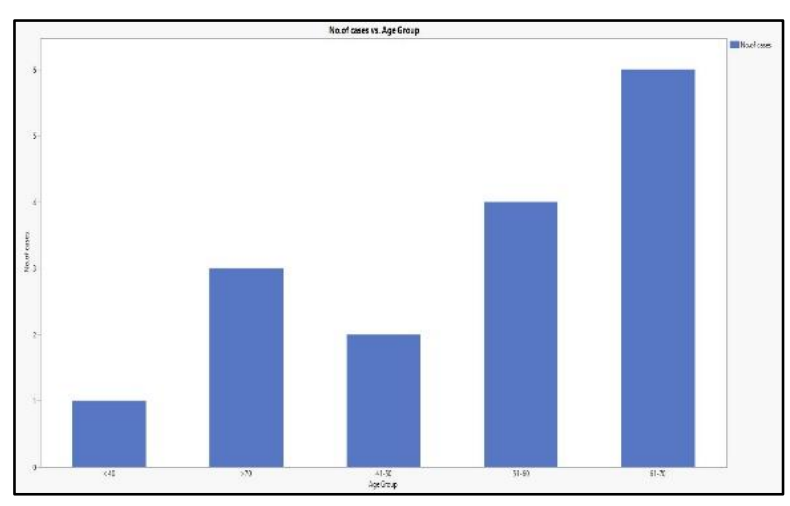

Figure 2: Correlation of age with incidence of endometrial cancer.

Papillary type was seen in 2 cases, while 1 case was diagnosed with mucinous variety. The most frequent type of endometrial carcinoma was Endometrioid carcinoma $81.2 \%$ followed by Papillary carcinoma representing $12.5 \%$ and Mucinous type $6.25 \%$ (Table 3). Papillary carcinoma was found in most advanced age group more than 70 years. (table 3). There was a significant relationship between endometrial carcinoma and age groups of patients and also that between histopathologic types of endometrial carcinoma and age groups of patients. Endometrioid was the most identified 
histopathologic type, while non- endometrioid type was seen in more advanced age category.

\section{DISCUSSION}

Incidence of endometrial cancer is on the rise approximately $3 \%$, increases with age and life expectancy 17 occurs during the reproductive and menopausal years. ${ }^{15,16,18}$ Historical observations have suggested that endometrial carcinomas vary in histopathologic appearance and clinical features. ${ }^{19}$ In 1983, Bokhman proposed that endometrial cancers could be divided into two broad types based on fundamental differences in endocrine and metabolic functioning and accepted endometrial cancer risk factors. ${ }^{19}$ Following Bokhman's seminal contribution, clinic-pathologic studies led to the view that the predominant form of endometrial cancer (referred to as Type I) corresponds histologically to endometrioid adenocarcinomas, whereas other forms (Type II) encompass most non-endometrioid histologic types. The most frequent type of endometrial carcinoma in our study was endometrioid carcinoma. Most of our cases were in age group of 60 and above.

\section{CONCLUSION}

Endometrial carcinoma was predominantly found in age 61 and above. The most frequent type of endometrial cancer identified in the study is endometrioid carcinoma. Non-endometrioid type which is more aggressive type of carcinoma was predominantly observed in advanced age group more than 70 years.

Funding: No funding sources

Conflict of interest: None declared

Ethical approval: Not required

\section{REFERENCES}

1. Balasubramaniam G, Sushama S, Rasika B. Mahantshetty. Hospital-based study of endometrial cancer survival in Mumbai, India. Asian Pacific Journal of Cancer Prevention. 2013;14(2):977-80.

2. Rose PG. Endometrial carcinoma. New England Journal of Medicine. 1996;335(9):640-9.

3. Dobrzycka B, Terlikowski SJ. Biomarkers as prognostic factors in endometrial cancer. Folia Histochemica et Cytobiologica. 2010;48(3):319-22.

4. Arafa M, Somja J, Dehan P. Current concepts in the pathology and epigenetics of endometrial carcinoma. Pathology. 2010;42(7):613-7.

5. Prat J, Gallardo A, Cuatrecasas M, Catas us L. Endometrial carcinoma: pathology and genetics. Pathology. 2007;39(1):72-87.
6. Zaino RJ, Kurman R, Herbold D. The significance of squamous differentiation in endometrial carcinoma: data from a Gynecologic Oncology Group study. Cancer. 1991;68(10):2293-302.

7. Sherman M. Theories of Endometrial Carcinogenesis: A Multidisciplinary Approach. Mod Pathol. 2000;13:295-308.

8. Mutch DG. The more things change the more they stay the same. Gynecol Oncol. 2012;124:3-14.

9. Wilson TO, Podratz KC, Gaffey TA, Malkasian GD Jr, O'Brien PC, Naessens JM. Evaluation of unfavorable histologic subtypes in endometrial adenocarcinoma. Am J Obstet Gynecol. 1990;162:418-23.

10. Emons G, Fleckenstein G, Hinney B, Huschmand A, Heyl W. Hormonal interactions in endometrial cancer. Endocr Relat Cancer. 2000;7:227-42.

11. Hameed K, Morgan DA. Papillary adenocarcinoma of endometrium with psammoma

12. bodies. Histology and fine structure. Cancer. 1972;29:1326-35.

13. Hamilton CA, Cheung MK, Osann K, Chen L, Teng NN, Longacre TA et al. Uterine papillary serous and clear cell carcinomas predict for poorer survival compared to grade 3 endometrioid corpus cancers. $\mathrm{Br}$ J Cancer. 2006;94:642-6.

14. Gusberg SB. Virulence factors in endometrial cancer. Cancer. 1993;71(4):1464-66.

15. American Society of Clinical Oncology. ASCO. Uterine cancer. Risk \& prevention. 2020. https://www.cancer.net/cancer-types/uterinecancer/risk-factors-and-prevention. Last accessed on 10th January 2021.

16. Leslie KK, Thiel KW, Goodheart MJ. Endometrial cancer. Obstet Gynecol Clin North Am. 2012;39(2):255-68.

17. Constantine GD, Kessler G, Graham S. Increased Incidence of Endometrial Cancer Following the Women's Health Initiative: An Assessment of Risk Factors. J Womens Health (Larchmt). 2019;28(2):237-43.

18. Alghamdi IG, Hussain II, Alghamdi MS. The incidence rate of corpus uteri cancer among females in Saudi Arabia: an observational descriptive epidemiological analysis of data from Saudi Cancer Registry 2001-2008. Int J Womens Health. 2014;6:141-7.

19. Pellerin GP1, Finan MA. Endometrial cancer in women 45 years of age or younger: a clinicopathological analysis. Am J Obstet Gynecol. 2005;193(5):1640-4.

20. Bokhman JV. Two pathogenetic types of endometrial carcinoma. Gynecol Oncol. 1983;15(1):10-7.

Cite this article as: Bharaswadkar G. Study of correlation between age with incidence of endometrial cancer and histopathological type. Int $\mathbf{J}$ Reprod Contracept Obstet Gynecol 2021;10:2473-5. 